У,

ББК 60.54

DOI 10.22394/1682-2358-2020-6-71-78

A.E. Kolobova, Candidate of Sciences (Sociology), Docent of the Labor and Production Complexes Economy Department, Yuri Gagarin State Technical University of Saratov

\section{OLDER RUSSIAN \\ WOMEN \\ ENTREPRENEURIAL \\ CAREER RESEARCH \\ IN CONTEXT \\ OF ADAPTATION \\ TO TRANSFORMING SOCIETY}

Older women entrepreneurial career in the adaptation context in a transforming society is analyzed. The article is based on the sociological research results in older Russian women entrepreneurial practices. The main features of elderly Russian women in business professional path are revealed. Models (options) of older women professional careers are formed.

Key words and word-combinations: entrepreneurship, professional path, older women, respondent, adaptation, transforming society.
A.E. Колобова, кандидат соииологических наук, дочент кафедрь экономики труда и произбодственных комплексов Саратовского государственного технического университета имени Гагарина Ю.А.

(email: kolobova_anna1@mail.ru)

\section{ИССАЕАОВАНИЕ}

ПРЕАПРИНИМАТЕАЬСКОЙ

КАРЬЕРЫ

РОССИЙСКИХ ЖЕНЩИН

СТАРШЕГО ВОЗРАСТА

В КОНТЕКСТЕ АААПТАЦИИ

К ТРАНСФОРМИРУЮШЕМУСЯ ОБЩЕСТВУ

Аннотация. Проанализировано развитие предпринимательских карьер женщин старшего возраста в контексте адаптации к трансформирующемуся обществу на основе результатов социологического исследования в России. Выявлены особенности их профессионального роста в бизнесе. Сформированы модели (варианты) профессиональной карьеры женщин данной категории.

Ключевые слова и словосочетания: предпринимательство, профессиональный путь, женщины старшего возраста, респондент, адаптация, транформирующееся общество.

конца XX в. и по настоящее время российское общество продолжает находиться в стадии трансформации. 
Специфика этих трансформаџионных проџессов состоит в том, что решающую роль в них играют так называемые субъектные факторы, то есть способность социальных субъектов реагировать на внутренние (в рамках данного социума) и внешние (со стороны миросистемы) вызовы [1, с. 11]. Типичным примером является предпринимательство, развивающееся в России с 1990-х годов. Состояние отечественного малого бизнеса, включающего мимлионы индивидуальных практик, влияет на трансформационные проџессы, хотя одновременно явцяется результатом изменений вектора государственной политики. Массовый приход россиян в сферу малого предпринимательства в начале 1990-х годов связан с попытками адаптации в меняющемся соџиуме. ААаптационные бизнесмодели активно осваивались женщинами [2-4], в том числе и преАставителями старшего возраста [5, с. 56], хотя им «инновационные» практики в сфере занятости давались трудно [6, с. 29]. Затянувшаяся на десятилетия общественная трансформация отражена в индивидуальных траекториях карьеры, профессионального пути в российском бизнесе. В начале 2000-х годов эксперты фиксировали немало заявок на гранты от мюдей предпенсионного и пенсионного возраста, и в современном российском обществе «возрастное предпринимательство» не является реАкостью: в 2017 г. около 1,5 млн человек в возрасте 50-72 лет имели собственное дело [7]. ПреАставцяется необходимым рассмотреть их особенности, в том числе в контексте аАаптаџии к указанным изменениям соџиума.

В качестве имлюстрации практик карьеры предпринимателя приведем Аанные социологического исследования, полученные с помошью метода опроса (глубинное интервью), выполненного в г. Саратове в 2008-2014 гг. Типичными респондентами выступили предпринимательниџы старшего возраста - все они являются представителями мелкого торгового бизнеса. Помимо них в опросе участвовали и другие группы респондентов от мужчин - наемных работников (в качестве родственников пожилых женщин-преАпринимателей) и мужчин-преАпринимателей молодого возраста до экспертов (сотрудников служб занятости). Выбор метоАа обусловлен прежде всего редкостью преАпринимательских практик среди российских пенсионеров (по возрасту). Выборка формировалась по принципу «снежного кома». Практически все опрошенные преАприниматели - женщины пенсионного возраста (старше 55 мет), цишь несколько респондентов входят в группу предпенсионного возраста. Посмеднее объясняется, в частности, тем, что в сфере торговли и малого бизнеса преобладают представители женского пола, это подтверждается и отечественными исследованиями [2-4].

Все респонденты начинали предпринимательскую карьеру в первой помовине 1990-х годов, когда они еще относились к Аемографической группе среднего возраста: 
«Начинала я примерно В 1994 2.» (59 лет);

«Я и сейчас это помню - В октябре 1995 г.» (69 мет).

Именно в этот период кризис охватывал большое число отечественных предприятий и сопровождался массовыми сокращениями. Наиболее уязвимой группой работников оказывацись женщины, это и стало основной причиной «выдавливания» преАставительниџ женского пола из сферы наемного труда и их вынужденного прихода в бизнес. Таким образом, практически все опрошенные женщины предпенсионного и пенсионного возраста явмяются «вынужденными предпринимателями». Аифференџиация предпринимателей на “добровольных» и «вынужденных» построена на мотивационном факторе. «Вынужденные предприниматели» приходят в бизнес под влиянием внешних факторов, и прежде всего безальтернативности получения дохода.

Такая классификация достаточно распространена в отечественной и зарубежной практике исследования предпринимательства. Например, ее используют в рамках проекта «ГАобальный мониторинг преАпринимательства» (Global Entrepreneurship Monitor - GEM) [8], участником которого является и Россия. О.Р. Верховская и Е.А. Александрова в своем

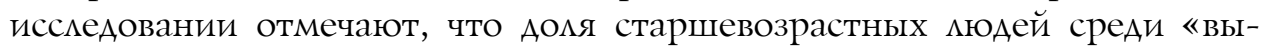
нужденных преАпринимателей» в России выше [9, с. 111]. ПреАполагаем, что среди пожилых предпринимательниц этот показатель еще выше, что, возможно, обусловлено совокупным негативным влиянием гендерного и возрастного факторов. Аискриминационные практики по возрастному признаку на рынке труда сохраняют актуальность и в современном мире $[10$, с. $10-11]$. Аискриминация на рынке труда в рассматриваемый период первой половины 1990-х годов проявилась максимально в отношении именно «возрастных» женщин. Последние были вынуждены адаптироваться к новым, сушественно ужесточившимся социально-экономическим условиям трансформирующегося общества и востребованной аАаптаџионной моделью Аля них и стало свое Аело.

Итак, принятие решения об открытии бизнеса среди респондентов (явцяюшееся в нашем понимании частью управления карьерой) было во многом продиктовано внешними обстоятельствами. ОАновременно зАесь проявилась высокая активность россиян в обустройстве своей жизни, отмечаемая В.А. ЯАовым [1, с. 14]. По нашему мнению, и то, и Аругое в совокупности могло оказать влияние и на Аальнейшее развитие их преАприниматемьской карьеры.

У всех опрошенных до открытия собственного бизнеса был опыт работы по найму. Типичное место работы респонденток - крупное промышиенное предприятие, которое явмяется характерным дмя советской экономики объектом хозяйствования. Маловероятно, что опыт работы в СССР мог как-то помочь в преАпринимательской карьере. Аолжности и специализация трудовой деятельности опрошенных - самые разные: 
«...работала я по сменам на шарикоподшипниковом заводе» (59 кет);

"Ао бизнеса я работала на нескольких работах. На разньх предприятиях» (57 мет);

«...я работала на складе ЦМС контролером группь химии» (69 мет);

«...Я работала на марксовском заводе "АГАТ» мастером иеха...» (52 года).

Примечательно, что ни у одной из опрошенных сфера прошлой работы по найму не связана со специализацией в предпринимательстве. Как уже отмечалось, все участниџы исследования - преАставители торгового бизнеса, преобладающего в отечественном предпринимательстве. Это объясняется и неразвитостью рыночной экономики в стране, и относительно невысокими барьерами входа в данный бизнес, а также быстротой оборота капитала в нем. Таким образом, выбор сферы деятельности опрашиваемых осушествлялся поА воздействием преимущественно внешних факторов.

Особо отметим, что некоторые женщины-предприниматели сделали Аостаточно непцохую карьеру, работая по найму:

«Работала на заводе им. Серго Орджоникидзе в отделе производства ведуиим диспетчером по производству в сборочном чехе» (69 ^ет);

«Раньше работала на складе заведующей - ответственность большая. Это тоже ответственность не только за себя, но и ответственность за других людей» (57 мет);

«..бъцла стариим инженером. На обойной фабрике. Это давно было, еше когда В Волгограде я жила» (71 гоА).

Прерывание вполне успешной карьеры, потеря высокого статуса в сфере наемной работы для таких респонденток было вынужденным шагом. Решение об уходе в бизнес в зрелом возрасте явно продиктовано негативным влиянием внешних обстоятельств. Предпринимательство явимось совершенно неизвестной сферой деятельности Аля россиян. ВряА $\Lambda и$ оно могло быть осознанным выбором, привлекательной сферой деятельности Аля женщин среднего и старшего возраста постсоветской России, очевидно, не имеющих необходимых знаний и навыков. В то же время бизнес стал вполне эффективным инструментом адаптации российских граждан в стремительно меняющихся политических и соџиально-экономических условиях российского соџиума конџа XX в. Они строили предпринимательскую карьеру, часто не имея никакого плана, стихийно, и проџесс этот, как правило, был слабоуправцяемым ици вообще неуправляемым.

Существенным фактором, обусловившим особенности траектории профессионального пути респонденток в бизнесе, стал формат начала предпринимательской деятельности. Возможны два варианта - официальный (в качестве зарегистрированного предпринимателя) и неофициальный (как представитель «теневого бизнеса»). В практике опрошенных присутствуют оба варианта. При этом, как было установлено,

74 Bulletin of the Volga Region Institute of Administration • 2020. Vol. 20. № 6 
в процессе ведения бизнеса статус менялся и опять же - с разАичными вариантами:

"С самого начала оформилась офиииально. Я вставала на уиет о государственной регистрачии предпринимателей по Һенинскому району города СаратоВа. Ааже дату помню - 25 октября 1995 г.» (69 кет);

«...Приилось совмешать работу на заводе и ИП: В будни работала, а по виходнигм виходила на рьгок торговать. Потом пошло поголовное сокращение производства на заводе, сократили, В том числе и меня. Открылла ИП и вишла на риток, но В те времена бъло не ИП, а лищензия (разрешение на торговлю), которая покупалась В администрачии. Причем ее можно бъло купить хоть на один день, хоть на месяи (насколько денег хватало), и ть свободно мог вьгити на рынок и торговать. А уже в 1997 г. стали вьгавать свидетельства ЧП (частньй предприниматель). Вот так я и стала предпринимателем» (52 года).

Фактор, опредемяющий выбор формата начала предпринимательской Аеятельности, не установлен. Некоторые респондентки начинали как «теневые преАприниматели», но затем получали офиџиальную регистрацию. Предполагаем, на такое решение влияли внешние факторы (например, активизаџия деятельности соответствующих контролирующих службб): "Сначала миг начали без документов. Нас начали налогобики гонять. Аа вич и сами знаете, как это бъъает» (71 гоА).

Часто «выход из тени» был связан и с развитием своего дела. По мере расширения бизнеса вести его «теневым способом» становится все сложнее, так как аренда / приобретение торговых площадей, работа с поставщиками, взаимодействия с клиентурой требуют наличия регистрационных документов: «Первое время неофиииально торговала, попозже дела пошли, офичиально оформилась» (59 мет).

При этом часть опрошенных никогда не практиковали ведение «теневого бизнеса» в мюбых его вариаџиях. Такой результат заставцяет сомневаться в утверждении о тотальности «теневого бизнеса» в России и безнадежности этой ситуации, на что часто указывают отечественные и зарубежные исследователи. В то же время результаты опроса позволяют сделать вывод о том, что в условиях российской действительности абсомютно «мегальный» бизнес - скорее искмючение, чем правицо. РеспонАенты уверены, что проблема «теневого» бизнеса в нашей стране есть, а формы его отличаются большим разнообразием:

«...Я видела, она [коллега-предпринимательница. А.К.] на базаре стояла, овощами торговала, которьге сьин где-то таскал [воровал - А.К.] " (59 мет);

"Аа, так [наруиение норм и законов В бизнесе. А.К.] биъвает. Но, конеино, ни В коем случае не нужно злоупотреблять своей клиентурой» (57 кет);

«Когда уже плоховато с торговлей стало, и все хуже и хуже, я сходила в налоговую и закрьла ИП. С чего я буду платить им, если торговли нет? Мне легие раз штраф отдать, чем ходить все время В налоговую свои денежки относить» (59 цет). 
Траектория профессионального пути в бизнесе у всех опрошенных включала этап официального ведения преАпринимательской деятельности. Часть опрошенных начинали дело как «теневики», а затем официально регистрировацись. Аругие начинали с регистрации, а затем, по мере сворачивания своего бизнеса, уходили в тень. Среди опрошенных есть и те, кто весь свой профессионацьный путь осуществцяли на мегальной основе. Возможно, это означает, что существуют внешние рычаги влияния на выведение бизнеса из «тени», но их эффективность невысока.

Все опрошенные пожилые женщины признали наличие положительных результатов профессиональной карьеры в преАпринимательстве. К таковым ими отнесены: «независимость от кого-то» (причем и финансовая, и социальная), «сам себе начальник», «можешь себе позволить тот же самый отпуск», «общение с мюдьми, и знакомства, и общие интересы в торговой сфере», «...Бизнес - это такой толчок, скажем, не только Амя цичного саморазвития». Таким образом, предпринимательская деятельность женщин старшего возраста способствует получению и сохранению ими экономических и соџиальных благ.

В целом выделены следующие модели (варианты) профессиональной карьеры пожилых женщин в предпринимательстве (таблица).

\section{Модели (варианты) профессиональной карьеры пожияых женщин в предпринимательстве}

\begin{tabular}{|c|c|c|c|}
\hline $\begin{array}{c}\text { Этапы } \\
\text { профессиональной } \\
\text { карьеры }\end{array}$ & Модель 1 & Модель 2 & Модель 3 \\
\hline $\begin{array}{l}\text { Этап } 1 . \\
\text { «Начало» }\end{array}$ & $\begin{array}{l}\text { В статусе «теневого } \\
\text { предпринимателя» }\end{array}$ & $\begin{array}{l}\text { В статусе «теневого } \\
\text { предпринимателя» }\end{array}$ & $\begin{array}{c}\text { В статусе } \\
\text { официально } \\
\text { зарегистрированного } \\
\text { предпринимателя }\end{array}$ \\
\hline $\begin{array}{l}\text { Этап } 2 . \\
\text { «Развитие» }\end{array}$ & $\begin{array}{c}\text { Официальная } \\
\text { регистрация } \\
\text { бизнеса }\end{array}$ & $\begin{array}{c}\text { Официальная } \\
\text { регистрация бизнеса }\end{array}$ & $\begin{array}{c}\text { Наращивание } \\
\text { оборотов в бизнесе, } \\
\text { привлечение в него } \\
\text { членов семьи }\end{array}$ \\
\hline $\begin{array}{l}\text { Этап } 3 . \\
\text { «Пик развития» }\end{array}$ & $\begin{array}{c}\text { Достижение } \\
\text { максимальных } \\
\text { оборотов в бизнесе }\end{array}$ & $\begin{array}{c}\text { Достижение } \\
\text { максимальных } \\
\text { оборотов в бизнесе }\end{array}$ & $\begin{array}{c}\text { Достижение } \\
\text { максимальных } \\
\text { оборотов в бизнесе }\end{array}$ \\
\hline $\begin{array}{l}\text { Этап } 4 . \\
\text { «Угасание» }\end{array}$ & $\begin{array}{c}\text { Постепенное } \\
\text { снижение } \\
\text { масштабов бизнеса } \\
\text { и уход в «тень» }\end{array}$ & $\begin{array}{c}\text { Постепенное } \\
\text { снижение масштабов } \\
\text { бизнеса }\end{array}$ & - \\
\hline $\begin{array}{l}\text { Этап } 5 . \\
\text { «Второе дыхание» }\end{array}$ & - & - & $\begin{array}{c}\text { Передача } \\
\text { бизнеса детям }\end{array}$ \\
\hline
\end{tabular}


Окончание таблищьы

\begin{tabular}{|c|c|c|c|}
\hline $\begin{array}{l}\text { Этап } 6 . \\
\text { «Уход» }\end{array}$ & $\begin{array}{c}\text { Постепенное свора- } \\
\text { чивание бизнеса } \\
\text { и уход из предпри- } \\
\text { нимательства }\end{array}$ & $\begin{array}{c}\text { Постепенное свора- } \\
\text { чивание бизнеса } \\
\text { и уход из предприни- } \\
\text { мательства }\end{array}$ & $\begin{array}{c}\text { Уход от управления } \\
\text { бизнесом }\end{array}$ \\
\hline $\begin{array}{l}\text { Этап } 7 . \\
\text { «Трансформация» }\end{array}$ & $\begin{array}{c}\text { Работа по найму } \\
\text { в сфере, отличного } \\
\text { от прежнего } \\
\text { бизнеса }\end{array}$ & $\begin{array}{c}\text { Работа по найму } \\
\text { в схожем бизнесе } \\
\text { (в качестве наемного } \\
\text { руководителя } \\
\text { или специалиста) }\end{array}$ & $\begin{array}{c}\text { Выполнение мелкого } \\
\text { функционала } \\
\text { в рамках семейного } \\
\text { бизнеса }\end{array}$ \\
\hline
\end{tabular}

Таким образом, исследование практик предпринимательской карьеры женщин предпенсионного и пенсионного возраста в контексте адаптации к условиям трансформирующегося российского общества позволяет сАемать следующие выводы.

Во-первых, принятие решения об открытии бизнеса (явмяющегося в понимании автора частью управления карьерой) было, с одной стороны, вынужденным (во многом продиктовано внешними обстоятельствам), а с Аругой стороны, принималось благодаря «высокоактивности» (термин В.А. ЯАова) россиян в обустройстве своей жизни.

Во-вторых, опыт работы по найму практически не вцияц на траекторию карьеры женщин в отечественном бизнесе, так как он был неактуальным по своему содержанию. Сфера бизнеса никак не связана с местом их прежней работы по найму. ОАнако нацичие управленческого опыта в работе по найму могло положительно сказаться на бизнескарьере.

В-третьих, несмотря на трудности, карьера в предпринимательстве принесла женщинам старшего возраста существенные экономические и социальные блага. Прежде всего, это доход от ведения бизнеса, обретение независимости, возможность саморазвития, а также сохранение коммуникаций и соџиального пространства в целом (что особенно важно в пожином возрасте).

В-четвертых, существует несколько модемей (вариантов) профессионального пути женщин зрелого и пожилого возраста в предпринимательстве, различающихся по этапам, формату начала бизнеса и другим показатемям. В Аальнейшем представляется необходимым исследование факторов, влияющих на специфику их предпринимательской карьеры.

B-пятых, степень управцяемости преАпринимательской карьеры женщин низка, что во многом связано с неразвитостью соответствующей институциональной среды. Развитие институтов бизнеса в российском обществе будет способствовать повышению эффективности Аанного рода экономической деятельности, а также ее популяризаџии среди насемения. 
B-шестых, сохраняется, на наш взглял, актуальность высказанной неоднократно еще в 1990-е годы идеи проекта поддержки предпринимательства социально уязвимых групп, включая граждан старшего возраста. Эффекты реализации данного проекта будут как экономическими, так и социокультурными. Подобные проекты необходимы не только преАставителям указанных групп, но и обществу, и государству в силу заинтересованности в более полном и эффективном использовании ресурсного потенциала всех слоев населения.

\section{Библиографический список}

1. Россия: трансформирующееся общество / под ред. В.А. Ядова. М., 2001.

2. Бабаева Л.В., Чирикова А.Е. Женщины в бизнесе // Социологические исследования. 1996. № 3. С. $75-81$.

3. Барсукова С.Ю. Специфика женского предпринимательства // Способы адаптации населения к новой социально-экономической ситуации в России. М., 1999. C. $71-85$.

4. Малютина Т.Г. Отличительные черты женского предпринимательства в России // Женское предпринимательство в экономике России и СНГ / сост. и общ. ред. Э.М. Ивановой. М., 2002. С. 91-94.

5. Доброхлеб В.Г. Ресурсный потенциал пожилого населения России // Социологические исследования. 2008. С. 55-61.

6. Григорьева И.А. Социальная политика и пожилое население в современной России: вызовы и возможности // Мир России. 2006. № 1. С. 29-49.

7. Зачем люди старше 55 лет создают стартапы? URL: https://www.vedomosti.ru/management/articles/2019/10/16/813920-zachem-lyudi-starshe

8. Global Entrepreneurship Monitor (GEM). URL: https://www.gemconsortium.org/

9. Александрова Е.А., Верховская О.Р. Мотивация предпринимательской активности: роль институциональной среды // Вестник Санкт-Петербургского университета. Сер. 8: Менеджмент. 2016. Вып. 3. С. 107-138.

10. Малеева T.M. [и др.]. Возрастные работники на российском рынке труда. M., 2016.

78 Bulletin of the Volga Region Institute of Administration • 2020. Vol. 20. № 6 